\title{
Diversity, utilization and proximate composition of indigenous leafy vegetables consumed in Malaysia
}

\begin{abstract}
The availability of indigenous leafy vegetables abundantly available in rural communities' surroundings plays important role in its sustainability. A study was conducted at three native markets in Bintulu Division of Malaysia: Bintulu (N

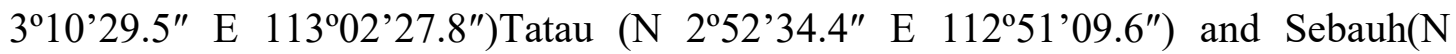
$\left.3^{\circ} 06^{\prime} 38.6^{\prime \prime} \mathrm{E} 112^{\circ} 16^{\prime} 05.7^{\prime \prime}\right)$ to determine the plant species frequently used as leafy vegetables by the locals. The structured questionnaire was distributed to identify the species consumed and gather the information on species used for food consumption, vernacular name and utilization methods. Twenty species from 18 different families were identified with Euphorbiaceae dominated by three species. The locals used the indigenous leafy vegetables (ILV) in the preparation of fried vegetables, eaten raw, fermented and seasoning. The proximate composition conducted on 13 species of ILV revealed that these vegetables contains significantly high moisture $(63.83-88.08 \%)$, fiber $(9.20-27.39 \%)$ and carbohydrate $(33.33-61.32 \%)$ contents whereas the fat $(0.09$ $-1.09 \%)$, proteins $(0.25-1.65 \%)$ and energy $(128.89-277.53 \mathrm{Kcal} / 100 \mathrm{~g})$ are low. The consumption of the ILV are recommended due to its potential to supply adequate intake of essential nutrients. Further study on the nutritional values of the ILV should be conducted to reveal many information on its nutritional values.
\end{abstract}

Keyword: Indigenous leafy vegetables; Native market; Bintulu; Utilization methods; Proximate 
